\title{
A fatal case of iatrogenic hypercalcemia after calcium channel blocker overdose
}

\author{
Michael T. Sim, $M D^{a}$, Frazier T. Stevenson, $M D^{b}$ \\ Department of Internal Medicine, University of California Davis, Sacramento, CA \\ aRenal fellow at UC Davis \\ bAssociate Professor of Clinical Medicine at UC Davis
}

\begin{abstract}
We report a case of a 61-year-old woman treated for a suspected verapamil overdose with continuous calcium chloride infusion, resulting in severe hypercalcemia of $32.3 \mathrm{mg} / \mathrm{dL}(8.07 \mathrm{mmol} / \mathrm{L})$ with a normal range of $8.6-10.5 \mathrm{mg} / \mathrm{dL}(2.15-2.63 \mathrm{mmol} / \mathrm{L})$. Treatment with acute hemodialysis rapidly normalized the serum calcium level, but the patient later died of vasoconstrictive complications of hypercalcemia.
\end{abstract}

\section{INTRODUCTION}

Extreme hypercalcemia is a relatively rare complication of therapeutic intravenous calcium infusion that can have severe vasoconstrictive complications. This case reveals an iatrogenic hypercalcemia unprecedented in published literature. While the judicious use of continuous calcium infusions may be useful for some calcium channel blocker overdoses, consequences of hypercalcemia may be deadly. Emergent dialysis quickly corrects severe hypercalcemia.

\section{CASE REPORT}

A 61-year-old woman was evaluated in the emergency department for bradycardia and hypotension. Approximately 5 hours prior to presentation, she reported inadvertently ingesting a single extra dose of verapamil SR $360 \mathrm{mg}$, which she took daily for longstanding essential hypertension and migraine headache prophylaxis. She denied suicidal ideation or intention. After experiencing presyncopal symptoms, she called 911 . En route to the medical center, the patient developed bradycardia with heart rate of 40 beats per minute and hypotension with systolic blood pressure of $60 \mathrm{mmHg}$. Paramedics administered $400 \mathrm{~mL}$ of 0.9 normal saline, then $1 \mathrm{mg}$ of atropine in the ambulance with a reported appropriate chronotropic response. On arrival, the patient was alert and conversant, but reported feeling "poor" and continued to have systolic blood pressure of about $60 \mathrm{mmHg}$. Initial electrolytes, BUN and creatinine were normal, and her serum glucose was $158 \mathrm{mg} / \mathrm{dL}(8.78 \mathrm{mmol} / \mathrm{L})$.

Two months prior, the patient had normal renal function (serum creatinine of $1.0 \mathrm{mg} / \mathrm{dL}$ or $88.5 \mathrm{umol} / \mathrm{L}$ ) and normal serum calcium $(8.7 \mathrm{mg} / \mathrm{dL}$ or $2.17 \mathrm{mmol} / \mathrm{L})$. The patient had a history of essential hypertension, migraine headaches, gastroesophageal reflux disease, and breast reduction surgery two months prior. The patient took verapamil SR $360 \mathrm{mg}$ daily, premarin $0.625 \mathrm{mg}$ daily, pantoprazole $40 \mathrm{mg}$ daily and daily multivitamin and calcium supplements.

Upon obtaining the history of verapamil ingestion, emergency department physicians attempted resuscitation with $2 \mathrm{~L}$ of bolus $0.9 \%$ saline, $5 \mathrm{~g}$ of calcium gluconate, $3 \mathrm{~g}$ of calcium chloride, $1 \mathrm{mg}$ of atropine, and $5 \mathrm{mg}$ of glucagon. After only marginal response, external pacing pads were placed. The patient was unable to tolerate cardiac pacing without sedation, thus endotracheal intubation was performed for airway protection. With high

Keywords: hypercalcemia, verapamil, calcium channel blocker toxicity, dialysis

Notes: There was no outside funding of any kind used for this study.

Corresponding Author: Frazier T. Stevenson, MD, Division of Nephrology, Department of Internal Medicine, PSSB 3500, UC Davis Medical Center, Sacramento, CA 95817. Phone: 916-734-3774. Fax: 916-734-7920. Email: frazier.stevenson@ucdmc.ucdavis.edu. 
output transcutaneous pacing to $140 \mathrm{~mA}$, electrical and mechanical capture was achieved with systolic blood pressure maintained above $140 \mathrm{mmHg}$.

Initial ECG tracings showed bradycardia but no evidence of ischemia, loss of $P$ waves or junctional/ventricular rhythms. The first set of cardiac enzymes showed myoglobin of $26 \mathrm{ng} / \mathrm{mL}$ (14-66 ng/mL) and troponin of $0.01 \mathrm{ng} / \mathrm{mL}(0-0.06 \mathrm{ng} / \mathrm{mL})$. Admission urinalysis showed no abnormalities.

Despite the uncertainty about the number of ingested verapamil tablets, toxicology consultants recommended an intravenous drip of calcium chloride at $4 \mathrm{~g}$ /hour (patient weight 85 $\mathrm{kg}$ ) and glucagon at $5 \mathrm{mg} /$ hour. No initial serum calcium level was drawn. Additionally, $4 \mathrm{~L}$ of GoLytely ${ }^{\circledR}$ was administered over 3-4 hours for whole bowel irrigation due to concerns that the patient erred in reporting the number of extra pills ingested. Charcoal gastric lavage was not done. Two hours later, the patient was transferred to the medical intensive care unit intubated and fully sedated. Cardiac pacing was initiated and she became hemodynamically stable, with a heart rate of 70 and systolic blood pressures of 120-140 mmHg. After 12 hours the pacemaker was discontinued, and blood pressure and pulse remained stable thereafter.

Approximately 1 hour after admission to the MICU, the first total calcium level was drawn and found to be $31.2 \mathrm{mg} / \mathrm{dL}(7.8$ $\mathrm{mmol} / \mathrm{L}$ ) with ionized calcium of $2.74 \mathrm{mmol} / \mathrm{L}$ (normal range $1.17-1.31 \mathrm{mmol} / \mathrm{L})$ (Table 1$)$ and phosphorus $1.4 \mathrm{mg} / \mathrm{dL}(0.45$ $\mathrm{mmol} / \mathrm{L})$. The calcium chloride intravenous drip was decreased to $2 \mathrm{~g} /$ hour and intravenous normal saline was increased to 500 $\mathrm{mL} /$ hour. To that point, the patient's urine output was measured between 75 and $125 \mathrm{~mL} /$ hour and serum creatinine was 1.1 $\mathrm{mg} / \mathrm{dL}(97.35 \mathrm{umol} / \mathrm{L})$. A repeat calcium level checked 8 hours later was $32.3 \mathrm{mg} / \mathrm{dL}(8.07 \mathrm{mmol} / \mathrm{L})$, and the calcium chloride drip was stopped.
In the next 6 hours, the patient's urine output diminished despite normal blood pressure and pulse. A repeat calcium level of $23.4 \mathrm{mg} / \mathrm{dL}(5.85 \mathrm{mmol} / \mathrm{L})$ was obtained (ionized calcium of $2.79 \mathrm{mmol} / \mathrm{L}$ ). When the patient became anuric, a nephrology consultation was obtained. Urine sediment showed many coarse granular casts consistent with acute tubular necrosis.

After placement of a dual-lumen hemodialysis catheter in the femoral vein, emergent renal replacement therapy was started. Continuous hemodialysis (CHD) was initiated with blood flow and dialysate flow at $200 \mathrm{~mL} / \mathrm{min}$ through a high flux dialyzer, using a zero calcium bath. Within 3 hours the patient's calcium level was $8.3 \mathrm{mg} / \mathrm{dL}(2.08 \mathrm{mmol} / \mathrm{L})$, and ionized calcium level was $1.27 \mathrm{mmol} / \mathrm{L}$.

Unfortunately, the patient remained anuric. Twenty-four hours later she developed acute elevations in hepatic transaminases, pancreatic enzymes, and cardiac markers, all despite consistent heart rates $>100 /$ minute and blood pressures $>110$ systolic without pacing or pressors. She developed progressive multi-organ failure despite daily continuous hemodialysis and continuous ventilator support. Systolic blood pressures were 95-160 without pressor support, and all blood/sputum cultures were no growth. The patient's clinical course worsened gradually, and she died 17 days after admission without recovering renal function.

Autopsy diagnosis reported acute tubular necrosis, massive liver necrosis, acute ischemic ileitis, multiple infarctions of the spleen, and bullous-vesicular skin lesions on the trunk and extremities, secondary to calciphylaxis confirmed by pathology post-mortem.

\section{DISCUSSION}

Several questions can be raised about the course of this patient's presentation and therapy.

\begin{tabular}{|c|c|c|c|c|c|c|c|c|}
\hline $\begin{array}{l}\text { Time (hours } \\
\text { from presentation) }\end{array}$ & 0 & 1 & 4 & 12 & 18 & 22 & 23 & 25 \\
\hline $\begin{array}{l}\text { Ca corrected } \\
(\mathrm{mg} / \mathrm{dL})^{*}\end{array}$ & $\mathrm{n} / \mathrm{a}$ & $\mathrm{n} / \mathrm{a}$ & 31.2 & 32.3 & 23.4 & 14.5 & & 8.3 \\
\hline $\begin{array}{l}\text { Ca ionized } \\
(\mathrm{mmol} / \mathrm{L})\end{array}$ & $\mathrm{n} / \mathrm{a}$ & $\mathrm{n} / \mathrm{a}$ & 2.74 & & & 2.79 & 1.32 & 1.27 \\
\hline $\begin{array}{l}\text { Creatinine } \\
(\mathrm{mg} / \mathrm{dL})\end{array}$ & 1.3 & & 1.1 & 1.8 & 2.4 & 2.6 & & 1.0 \\
\hline $\begin{array}{l}\text { Urine Output } \\
\text { (mL/hour) }\end{array}$ & & 115 & 110 & 75 & 50 & 20 & 10 & \\
\hline \multirow[t]{5}{*}{ Treatments } & $5 \mathrm{~g}$ calcium & calcium & calcium & Calcium & & Continuous & & \\
\hline & gluconate, & chloride & chloride & chloride & & hemodialysis & & \\
\hline & $3 \mathrm{~g}$ calcium & infused at & infusion & infusion & & started & & \\
\hline & chloride & $4 \mathrm{~g} / \mathrm{hr}$ & reduced to & stopped & & & & \\
\hline & & & $2 \mathrm{~g} / \mathrm{hr}$ & & & & & \\
\hline
\end{tabular}




\section{Was the initial management and use of a calcium drip appropriate?}

It is uncertain if this patient had a verapamil overdose. Her bradycardia could have been caused by ischemic heart disease, even though there was no prior history of this and no acute ECG findings. The patient claimed to have ingested only one additional dose of verapamil, and no verapamil level was sent (this is rarely done at our ED since is not generally returned fast enough to guide acute management). The treating physicians felt that an overdose was likely given the degree of hypotension and bradycardia, and initiated therapy based on the acuity of the patient.

Initial intravenous fluid resuscitation and mechanical ventilation (to allow sedation for pacing) were appropriate for treating her bradycardia. Since the patient ingested the verapamil many hours prior to presentation, orogastric lavage with activated charcoal was not performed, but whole bowel irrigation was given to remove the extended release preparation. Other therapies included injections of atropine, glucagon, and calcium, none of which were initially effective. There was no attempt to use pressors or highdose insulin, which have been shown to be effective [2].

The use of large doses of intravenous calcium can reverse calcium channel blocker toxicity [3], even if the patient does not have a sustained hemodynamic improvement with its initial use. This has been demonstrated in several case reports (Table 2) [4-7]. Except for Oe, et al. [4], these demonstrated that cautious use of continuous intravenous calcium infusions with close surveillance of serum calcium levels was successful in treating calcium channel blocker toxicity.

There is no established maximum dose of calcium for the treatment of calcium channel toxicity. Good results have been reported with calcium dosed between 0.2 and $3.8 \mathrm{~g}$. [5] In one case, a patient received $30 \mathrm{~g}$ of calcium with subsequent peak calcium level of $23.8 \mathrm{mg} / \mathrm{dL}(5.95 \mathrm{mmol} / \mathrm{L})$ with successful reversal of conduction delay [6]. In animal studies, doubling and tripling of ionized calcium levels are sometimes needed $[7,8]$. Current recommendations for calcium infusion are $0.2-0.4 \mathrm{~mL} / \mathrm{kg} / \mathrm{hr}$ of $10 \%$ $\mathrm{CaCl}$, or approximately $1.7 \mathrm{~g} / \mathrm{hr}$ in a $85-\mathrm{kg}$ patient such as this case $[3,9,10]$. In this case, the calcium infusion was started at $4 \mathrm{~g} / \mathrm{hr}$, prior to checking the serum calcium level, and was continued despite subsequent severe hypercalcemia. Ultimately, the patient received at total of $38 \mathrm{~g}$ of calcium but developed multi-organ failure despite prompt reversal of bradycardia, and normotension following the first 3 hours of hospitalization. Monitoring of clinical symptoms of hypercalcemia and evidence of vasoconstriction such as oliguria is paramount to successful use of calcium infusions.

\section{What were the consequences of severe hypercalcemia in this patient?}

Acute hypercalcemia of the magnitude seen in this patient is unprecedented in our literature search. Our laboratory regards serum calcium up to $10.5 \mathrm{mg} / \mathrm{dL}(2.63 \mathrm{mmol} / \mathrm{L})$ as normal. There are no uniform recommendations about what level of hypercalcemia warrants aggressive therapy, and the acuity of onset may be important in patient tolerance. One study showed symptomatic improvement in $25-30 \%$ of patients post-parathyroidectomy who had modest (12-14 mg/dL) and presumably chronic hypercalcemia [11]. However, more severe hypercalcemia has been tolerated in many cases studies during calcium infusions in treatment of calcium channel blocker overdose [12-14]. For example, one

Table 2: Comparison of Case Reports

\begin{tabular}{lllll}
\hline & Oe et al. [4] & Hung et al. [12] & Lam et al. [13] & Isbister [14] \\
\hline CCB ingested & Verapamil & Amlodipine & Nifedipine & Diltiazem \\
\hline Quantity ingested $(\mathrm{g})$ & 3.6 & 0.3 & 4.2 & $1.8-3.6$ \\
\hline Lowest blood pressure $(\mathrm{mmHg})$ & $54 / 32$ & $70 / 42$ & $70 / 30$ & asystole \\
\hline Lowest heart rate (beats $/$ minute) & 54 & 78 & 115 & asystole \\
\hline Total calcium salts infused $(\mathrm{g})$ & None & 13 & Approximately 8 & 14.5 \\
\hline Other treatments used & $1,2,4$ & $1,2,3,4$ & $1,2,4,5$ & $1,2,5,10 \mathrm{mg}$ \\
& $(20 \mathrm{mcg} / \mathrm{kg} / \mathrm{min})$, & $(10 \mathrm{mcg} / \mathrm{kg} / \mathrm{min})$ & & $\begin{array}{l}\text { epinephrine, } \\
\text { epinephrine IV } \\
\text { gtt }(6 \mathrm{mg} / 100 \mathrm{~mL} \\
\text { at } 5 \mathrm{~mL} / \mathrm{hr}), \\
\text { dobutamine IV gtt, } \\
\text { bicarbonate infusion, } \\
\text { CVVH for } 24 \mathrm{hours}\end{array}$ \\
\hline
\end{tabular}

1 = intravenous fluids

2 = gastric lavage with charcoal

3 = furosemide

4 = dopamine intravenous drip

$5=$ norepinephrine intravenous drip 
patient tolerated a serum calcium of $15.1 \mathrm{mg} / \mathrm{dL}(3.78 \mathrm{mmol} / \mathrm{L})$ with close monitoring with successful treatment of amlodipine overdose [12].

A striking clinical finding in this patient was initial polyuria, likely caused by nephrogenic diabetes insipidus from an inability to maximally concentrate urine due to a defect in $\mathrm{NaCl}$ transport in the ascending limb of the loop of Henle. However, the patient later became oliguric, likely the result of calcium-induced vasoconstriction [15]. The acute tubular necrosis suggested by urinalysis would be expected from intense vasoconstriction, but could also have been caused by the initial hypotension.

Studies in rat and dog kidneys subjected to elevated blood calcium levels show renal vascular hyperresponsiveness and increased renal vascular resistance [16-18]. An intense vasoconstriction induced by hypercalcemia is also supported by the multiple infarctions and necrosis of the liver, gut, spleen, and kidneys seen at autopsy.

Although the authors believe that hypercalcemia was the main instigating factor for the patient's presentation, other medical conditions may have contributed to her eventual demise. Although the patient did suffer from transient hypotension due to the calcium channel blocker toxicity, that is unlikely to have been the only cause of the numerous post-mortem ischemic injuries. The transient hypotension could also have been due to acute coronary ischemia prior to admission, since the patient did eventually develop elevated cardiac markers. The patient may have developed shock and bradycardia from an etiology other than calcium channel blocker overdose, though that was not discovered during her hospitalization. Her hypotension, given its short duration and moderate level, could have contributed to her death but is unlikely to be its sole precipitant.

Calciphylaxis was discovered in the patient by autopsy. Otherwise known as calcific uremic arteriolopathy, this is a rare, poorly understood disorder of mineral metabolism [19]. Typically associated with patients with end-stage renal disease, many factors including hyperparathyroidism, hypercalcemia, hyperphosphatemia, and defects in coagulation have been implicated, but none is a uniform or consistent finding in cases. No cases have been reported in calcium infusions, such as in this case. Longstanding calciphylaxis will manifest as ischemic necrosis of the skin, fat and muscle of the lower extremities and pannus with an appearance of violaceous eschar-like wounds. Earlier in the disease, as in this patient, histology will show arterial occlusion with medial calcification without vasculitic changes [20].

\section{How should the iatrogenic hypercalcemia have been treated?}

Reviews of treatment for hypercalcemia, even hypercalcemic crisis, have not addressed levels as elevated as in this patient. This patient did not have serum calcium measured prior to start of calcium infusion. After the initial serum calcium level of $31.2 \mathrm{mg} / \mathrm{dL}$ ( $7.8 \mathrm{mmol} / \mathrm{L}$ ) was discovered, the calcium chloride infusion was decreased, but not stopped. The infusion was not stopped until 8 hours later, presumably placing the patient at higher risk for vasoconstrictive complications. The physicians apparently were more focused on treating the presumed verapamil overdose than the hypercalcemia during this period.

After eventual discontinuation of the calcium chloride, the patient was treated with saline infusion, which was only partially effective in reducing the calcium level. Other conservative treatments such as furosemide-induced diuresis, corticosteroids, bisphosphonates or calcitonin were not started concurrently, but they would likely be at best partially effective at this level of hypercalcemia and potentially unsafe since the patient's renal function was declining.

Several reports have shown that hemodialysis and peritoneal dialysis with low calcium baths are effective in controlling hypercalcemia [21,22]. Approximately $60 \%$ of calcium in plasma is unbound to protein and is readily dialyzed by either hemodialysis or peritoneal dialysis [23]. In this case, hemodialysis was chosen due to our ability to initiate this modality quickly. Previous studies have shown that calcium flux is dependent on the concentration gradient between dialysate and blood [24]. In fact, that relationship may be linear [25]. Thus it is not surprising that we corrected her calcium quickly using a high flux dialyzer (Fresenius 2008K dialysis system with a Gambro Polyflux H kidney) and a zero calcium hemodialysis bath. Standard intermittent hemodialysis likely would have been adequate to treat the hypercalcemia since the intravenous infusion had been discontinued by then. However, we chose continuous hemodialysis for better solute control. Her serum calcium levels quickly returned to normal. Had dialysis started earlier, at least some sequelae may have been avoided.

We concur with Koo et al. [21] in recommending initiation of hemodialysis for hypercalcemia in cases when less invasive interventions such as saline infusions, loop diuretics, bisphosphonates and calcitonin have not reduced calcium to a desired level and the patient is symptomatic. Additionally, if the patient, as in this case, becomes oliguric or has acute kidney injury, dialysis may be more effective and safer than the aforementioned therapies.

Although the patient's autopsy revealed lesions consistent with calciphylaxis, we did not suspect this diagnosis, as the patient did not have typical skin lesions. Control of serum calcium with dialysis is an important component of treatment of calciphylaxis, though sodium thiosulfate may have benefit as well [26].

\section{CONCLUSION}

This case report demonstrates a unique severity and morbid consequence of iatrogenic hypercalcemia used in treating a presumed verapamil overdose. The case identifies three important points: high-dose intravenous calcium infusion must be used judiciously and with close monitoring in treating calcium channel blocker overdose; acute, severe hypercalcemia can provoke vasoconstrictive complications; and hemodialysis should be considered early as part of the treatment for severe hypercalcemia in order to achieve normocalcemia as quickly as possible. 


\section{REFERENCES}

1. Orrell DH. Albumin as an aid to the interpretation of serum calcium. Clin Chim Acta Dec 1971;35(2):483-489.

2. Shepherd G. Treatment of poisoning caused by $\beta$-adrenergic and calcium channel blockers. Am J Health-Syst Pharm Oct 2006;63:1828-1835.

3. Kerns W, Kline J, Ford MD. Beta-blocker and calcium channel blocker toxicity. Emerg Med Clin North Am May 1994; $12(2): 365-390$.

4. Oe H, Taniura T, Ohgitani N. A case of severe verapamil overdose. Jpn Circ J 1998;62:72-76.

5. Ramoska EA, Spiller HA, Winter M, et al. A one-year evaluation of calcium channel blocker overdoses: toxicity and treatment. Ann Emer Med Feb 1993;22(2):196-200.

6. Buckley NA, Dawson AH, Howarth DM. Slow release verapamil poisoning. Use of polyethylene glycol whole bowel lavage and high-dose calcium. Med J Aust 1993;6:408-430.

7. Kline J, Leonova E, Raymond RM. Beneficial myocardial effects of insulin during verapamil toxicity in the anesthetized canine. Crit Care Med Jul 1995;23(7):1251-1263.

8. Hariman RJ, Mangiardi LM, McAllister RG, et al. Reversal of the cardiovascular effects of verapamil by calcium and sodium: differences between electrophysiologic and hemodynamic responses. Circ Apr 1979;59(4):797-804.

9. Kenny J. Treating overdose with calcium channel blockers. BMJ Apr 1994;308(6935):992-993.

10. Pearigen PD, Benowitz NL. Poisoning due to calcium antagonists. Experience with verapamil, diltiazem and nifedipine. Drug Saf Nov-Dec 1991;6(6):408-430.

11. Chan AK, Duh QY, Katz MH, Siperstein AE, Clark OH. Clinical manifestations of primary hyperparathyroidism before and after parathyroidectomy. A case-control study. Ann Surg 1995 Sep;222(3):402-412.

12. Hung Y, Olson KR. Acute amlodipine overdose treated by high dose intravenous calcium in a patient with severe renal insufficiency. Clin Tox 2007;45:301-303.

13. Lam, Y, Tse, H, Lau, C. Continuous calcium chloride infusion for massive nifedipine overdose. Chest 2001; 119:1280-1282.
14. Isbister GK. Delayed asystolic cardiac arrest after diltiazem overdose: resuscitation with high dose intravenous calcium.

Emerg Med J 2002;19:355-357.

15. Brenner BM, Levy E, Hostetter TH. Tubulointerstitial diseases of the kidney. In: Fauci AS, editor. Harrison's Principles of Internal Medicine (14 ${ }^{\text {th }}$ ed.). New York: McGraw-Hill, 1998. pp 276-80.

16. Pargger H, Kaufmann MA, Drop LJ. Renal vascular hyperresponsiveness to elevated ionized calcium in spontaneously hypertensive rat kidneys. Intensive Care Med Jan 1998;24(1): 61-70.

17. Castelli I, Steiner LA, Kaufmann MA, Drop LJ. Renovascular responses to high and low perfusate calcium steady-state experiments in the isolated perfused rat kidney with baseline vascular tone. J Surg Res Feb 1996;61(1):51-57.

18. Kover G, Tost H. Effects of hypercalcemia on kidney function in anesthetized dogs. Acta Physiol Hung 1993;81(4):971-993.

19. Adrogue HJ, Frazier MR, Zeluff B, et al. Systemic calciphylaxis revisited. Am J Nephrol 1981;1(3-4):177-183.

20. Essary LR, Wick MR. Cutaneous calciphylaxis. An underrecognized clinicopathologic entity. Am J Clin Pathol Feb 2000;113(2):280-287.

21. Koo WS, Jeon DS, Ahn SJ, et al. Calcium-free hemodialysis for the management of hypercalcemia. Nephron 1996; 72(3):424-428

22. Shigematsu T, Kawaguchi Y, Kubo H, et al. Low calcium $(1.25 \mathrm{mmol} / \mathrm{L})$ dialysate can normalize relative hypoparathyroidism in CAPD patients with low bone turnover. Adv Perit Dial 1996; $12: 250-256$

23. Schulman G, Himmelfarb J. Hemodialysis. Brenner and Rector's The Kidney (7th ed.). Brenner BM, editor. Philadelphia: Saunders Co., 2004. pp 2578-2588.

24. Sigrist M, McIntyre CW. Calcium exposure and removal in chronic hemodialysis patients. J Ren Nutr Jan 2006;16(1):41-46.

25. Strong HE, Schatz BC, Shinaberger JH, et al. Measurement of dialysance and bi-directional fluxes of calcium in vivo using radiocalcium. Trans ASAIO 1971;17:108-115.

26. Don BR, Chin AI. A strategy for the treatment of calcific uremic arteriolopathy (calciphylaxis) employing a combination of therapies. Clin Nephrol Jun 2003;59(6):463-470. 